\title{
DATING OF ANCIENT ICONS FROM KIEV ART COLLECTIONS
}

\author{
N Kovalyukh ${ }^{1}$ J van der Plicht $^{2} \bullet \mathrm{G}^{\text {Possnert }^{3}} \bullet \mathrm{V}_{\text {Skripkin }}{ }^{\bullet}$ L Chlenova $^{4}$ \\ ABSTRACT. Icon painting in the Ukraine is rooted in the Byzantine culture, after the conversion to the Christian religion. \\ During the medieval epoch, Kiev became the artistic center for highly skilled icon painters. The icons were painted on wooden \\ boards, specially made for this purpose. Historic dating of some even well-known icons is uncertain or not precise. Here we \\ present for the first time radiocarbon dates for selected icons. Both liquid scintillation counting (LSC) and accelerator mass \\ spectrometry (AMS) dating methods were applied, allowing intercomparison.
}

\section{INTRODUCTION}

Icon painting in the Ukraine (as well as in other Slavic countries) succeeded the Antique and Byzantine cultures, following the conversion to the Christian religion (Bertie-Delagard 1910). Kiev and surroundings developed into a major location for icon art. The icon painters from Kiev were famous and highly skilled. They created icons which were very valuable and revered as precious relics. The most outstanding icons originate from the XIIth to the first half of the XIIIth century AD.

The artistic traditions originating in Kiev remained, even after the decline of the Kiev empire. The cultural center moved westward, to the Galitsco-Volynskoye principality. Here new art centers developed, and the Ukrainian art painting style was brought to perfection. Byzantine and WestRoman stylistic influences can still be recognized.

The XIV-XV centuries must be considered as the "Golden Age" of icon painting in the Ukraine. This is also recognized in architecture, such as the iconostasis. Icons become colorful and versatile in style; the artists are considered to be the National Painting School. The art centers in western Ukraine-Galitsia, Volyn and others-kept flourishing, despite wars ravaging the lands (Chlenova 1999).

\section{DATING THE ICONS}

Historic dating of some even well-known icons is uncertain. For this reason, radiocarbon dating has been performed for selected icons. The icons are all painted on wooden boards, specially made for the purpose of icon painting. Chips of wood were taken from the edges of the boards, which correspond to the youngest treerings-i.e. material best representing the time of painting.

The wood was pretreated chemically using standard techniques, and ${ }^{14} \mathrm{C}$ dated by three laboratories: Kiev, Ukraine (laboratory code Ki), Groningen, Netherlands (laboratory code GrA), and Uppsala, Sweden (laboratory code Ua). The Kiev laboratory is conventional, using liquid scintillation counting (LSC) (Skripkin et al. 1998); Groningen and Uppsala use applied accelerator mass spectrometry (AMS) (Gottdang et al. 1995; Possnert et al. 1990).

This project also allows intercomparison of two ${ }^{14} \mathrm{C}$ methods (AMS and LSC), because the ${ }^{14} \mathrm{C}$ results can be compared to the historical dates (when known) of the icons.

The results are shown in Table 1 . The ${ }^{14} \mathrm{C}$ dates are calibrated using the Groningen calibration program CAL25 (van der Plicht 1993), upgraded with the latest recommended calibration curve

\footnotetext{
${ }^{1}$ National Academy of Sciences, Kiev, Ukraine

${ }^{2}$ Centre for Isotope Research, Groningen, the Netherlands. Corresponding author. Email: plicht@phys.rug.nl.

${ }^{3}$ Tandem Accelerator Laboratory, Uppsala, Sweden

${ }^{4}$ National Art Gallery, Kiev, Ukraine
}

(C) 2001 by the Arizona Board of Regents on behalf of the University of Arizona

Radiocarbon, Vol 43, Nr 2B, 2001, p 1065-1075

Proceedings of the 17 th International ${ }^{14} \mathrm{C}$ Conference, edited by I Carmi and E Boaretto 
INTCAL98 (Stuiver and van der Plicht 1998). The probability of the calibrated ages is indicated by the $1 \sigma$ and $2 \sigma$ time-interval ranges. The numbers are rounded off. In cases where the range has two solutions, their relative probability is given in the last column of Table 1.

\section{DISCUSSION AND CONCLUSIONS}

Seven icons were selected for ${ }^{14} \mathrm{C}$ dating, all unique pieces of art. The ${ }^{14} \mathrm{C}$ results are generally in agreement with the ages expected on historical grounds. It is known that the artists prepared wooden boards for each icon separately; the time between the preparation of the board and the actual painting of the icon was not more than approximately 10 years. For our ${ }^{14} \mathrm{C}$ analysis, most samples were taken from the edges of the boards, which correspond to the youngest parts of the wood. Our ${ }^{14} \mathrm{C}$ measurements are consistent with a short time span between wood preparation and actual painting.

Table $1{ }^{14} \mathrm{C}$ dating results for icons painted on wood

\begin{tabular}{|c|c|c|c|c|c|c|}
\hline \multirow[b]{2}{*}{ Lab nr } & \multirow[b]{2}{*}{ Icon } & \multirow{2}{*}{$\begin{array}{l}\text { Historical } \\
\text { date } \\
\text { (cent. AD) }\end{array}$} & \multirow{2}{*}{$\begin{array}{c}{ }^{14} \mathrm{C} \text { date } \\
\text { (BP) }\end{array}$} & \multicolumn{2}{|c|}{ Calibrated age (cal AD) } & \multirow{2}{*}{$\begin{array}{c}\text { Probability } \\
\%\end{array}$} \\
\hline & & & & $1 \sigma$ & $2 \sigma$ & \\
\hline Ki-8018 & St George with scenes from his life & XII-XIII & $1010 \pm 45$ & & & \\
\hline $\mathrm{Ki}-8019$ & St George with scenes from his life & & $1055 \pm 40$ & & & \\
\hline $\mathrm{Ki}-8020$ & St George with scenes from his life & & $970 \pm 40$ & & & \\
\hline Averaged & St George with scenes from his life & & $1010 \pm 25$ & $1000-1025$ & $\begin{array}{r}985-1040 \\
1140-1150\end{array}$ & $\begin{array}{c}93 \\
7\end{array}$ \\
\hline GrA-15255 & The Intercession & XI & $1030 \pm 40$ & & & \\
\hline $\mathrm{Ki}-8017$ & The Intercession & & $1065 \pm 50$ & & & \\
\hline $\mathrm{Ki}-8024$ & The Intercession & & $1050 \pm 45$ & & & \\
\hline $\mathrm{Ki}-8025$ & The Intercession & & $1090 \pm 45$ & & & \\
\hline Averaged & The Intercession & & $1055 \pm 20$ & $985-1015$ & $\begin{array}{l}905-915 \\
975-1020\end{array}$ & $\begin{array}{c}5 \\
95\end{array}$ \\
\hline GrA-10120 & The Virgin Hodegetria of Volyn & XIII-XV & $600 \pm 35$ & & & \\
\hline $\mathrm{Ki}-8026$ & The Virgin Hodegetria of Volyn & & $645 \pm 40$ & & & \\
\hline Averaged & The Virgin Hodegetria of Volyn & & $620 \pm 25$ & $1305-1390$ & $1300-1400$ & \\
\hline GrA-10121 & The Apostles Peter and Paul & $\mathrm{XV}$ & $355 \pm 35$ & & & \\
\hline Ki-8027 & The Apostles Peter and Paul & & $320 \pm 45$ & & & \\
\hline Ua-13482 & The Apostles Peter and Paul & & $330 \pm 65$ & & & \\
\hline Averaged & The Apostles Peter and Paul & & $340 \pm 25$ & $\begin{array}{l}1490-1525 \\
1560-1630\end{array}$ & $1485-1640$ & $\begin{array}{l}35 \\
65\end{array}$ \\
\hline GrA-15253 & Boris and Gleb & XIII & $815 \pm 40$ & & & \\
\hline GrA-15254 & Boris and Gleb & & $775 \pm 35$ & & & \\
\hline $\mathrm{Ki}-8015$ & Boris and Gleb & & $790 \pm 45$ & & & \\
\hline $\mathrm{Ki}-8016$ & Boris and Gleb & & $840 \pm 40$ & & & \\
\hline Averaged & Boris and Gleb & & $805 \pm 20$ & $1220-1255$ & $1215-1270$ & \\
\hline GrA-15252 & St George and the Dragon & $\mathrm{XV}$ & $455 \pm 35$ & $1425-1465$ & $1410-1485$ & \\
\hline Ua-15999 & St George and the Dragon & & $570 \pm 50$ & $1305-1415$ & $1300-1435$ & \\
\hline GrA-15256 & Christ in Majesty & $X V$ & $450 \pm 35$ & $1425-1465$ & $\begin{array}{l}1410-1485 \\
1605-1610\end{array}$ & $\begin{array}{c}97 \\
3\end{array}$ \\
\hline
\end{tabular}


Here we briefly discuss the seven studied icons with their ${ }^{14} \mathrm{C}$ dates; for a full description of the icons we refer to the literature (Chlenova 1999).

\section{Saint George with Scenes from His Life}

This is one of the oldest and precious icons studied (Figure 1; see Appendix for figures). It is a piece of Byzantine art, and represents the early stage of image iconography (Miliaieva 2000). The icon has been dated by art historians to the XII-XIIIth century AD. ${ }^{14} \mathrm{C}$ dating shows that the wood icon is actually somewhat older-XIth century.

\section{The Intercession}

This is a wooden icon from Galitsia (western Ukraine), historically dated to the XII-XVth century $\mathrm{AD}$ (Figure 2). The icon is one of the oldest with the intercession theme. Also here, ${ }^{14} \mathrm{C}$ dating shows that the icon actually dates from the XIth century. This old age raises questions concerning Kievor Byzantine-origin of the artwork.

\section{The Virgin Hodegetria of Volyn}

This icon (Figure 3) represents the time when Byzantine influence was about to disappear from the Slavic countries, including Ukraine. The expected age is XIII-XVth century AD. ${ }^{14} \mathrm{C}$ measurement shows that the icon dates from the first half of the XIVth century.

\section{The Apostles Peter and Paul}

This icon (Figure 4) is described in historic literature, and supposed to date from the second half of the XVth century AD. A possible older date-even the XIIth century-could not be excluded, so confirmation by ${ }^{14} \mathrm{C}$ was needed. The literature appears to be correct according to our ${ }^{14} \mathrm{C}$ measurements.

\section{Boris and Gleb}

This icon (Figure 5) is now dated by ${ }^{14} \mathrm{C}$ to the XIIIth century AD. The icon thus appears to be one of the earliest art monuments portraying these Russian Saints, sons of Prince Volodymyr who were canonized by the church in 1072 as martyrs.

\section{Saint George and the Dragon}

Two samples from different parts of the wood were selected for ${ }^{14} \mathrm{C}$ analysis. One sample, representing younger treerings, was measured in Groningen (GrA-15252), the other sample was taken from a central part of the wooden board and is measured in Uppsala (Ua-15999). Indeed the ${ }^{14} \mathrm{C}$ ages show this difference. The samples are about 25 annual rings apart, which is consistent with the measurements taking the calibration curve into account. The icon (Figure 6) dates from the second half of the $\mathrm{XVth}$ century.

\section{Christ in Majesty}

The "Christ in Majesty" theme is a focus for icon painting during the XV-XVIth centuries. Such icons were always placed at the center of the iconostasis. This icon (Figure 7) is very famous and originates from the village Malniv. It was painted in the second half of the XVth century by "the Rublevians" (Gordynskyi 1973). This is corroborated by ${ }^{14} \mathrm{C}$ analysis (GrA-15256, $450 \pm 35 \mathrm{BP}$ ). 


\section{REFERENCES}

Bertie-Delagard AL. 1910. On the history of Christianity in Crimea. Fictitious Millennium, Fancy and Reality in the History of St. George's Monastery in Balaklava. Proceedings of Imperial Odessa Society of History and Antiquities, Odessa, 1910. Volume XXVIII. p 171; supplement p 72-108.

Chlenova LG. 1999. Masterpieces of Ukrainian iconpainting of the 12th-19th centuries. Kiev. ISBN 966577-035-7.

Gottdang A, Mous DJW, van der Plicht J. 1995. The HVEE system at Groningen. Radiocarbon 37(2):649_ 56.

Gordynskyi S. 1973. Ukrainian icons of the 12th-18th centuries. Philadelphia.

Miliaieva L. 2000. Report at the workshop "The Glory of

Byzantium”, Metropolitan Museum of Art, 1997. Mariupol Icon "St. George with Scenes from His Life." Chronicle 33:305-19.

van der Plicht J. 1993. The Groningen Radiocarbon Calibration Program. Radiocarbon 35(1):231-7.

Possnert G. 1990. Radiocarbon dating by the accelerator technique. Norwegian Archaeological Review 23(12):30-7.

Skripkin V, Kovalyukh N. 1998. Recent developments in the procedures used at the SSCER laboratory for the preparation of Lithium Carbide. Radiocarbon 40(1): 211-4.

Stuiver M, van der Plicht J, editors. 1998. INTCAL98: calibration issue. Radiocarbon 40(3):1041-162. 


\section{APPENDIX: FIGURES 1-7}

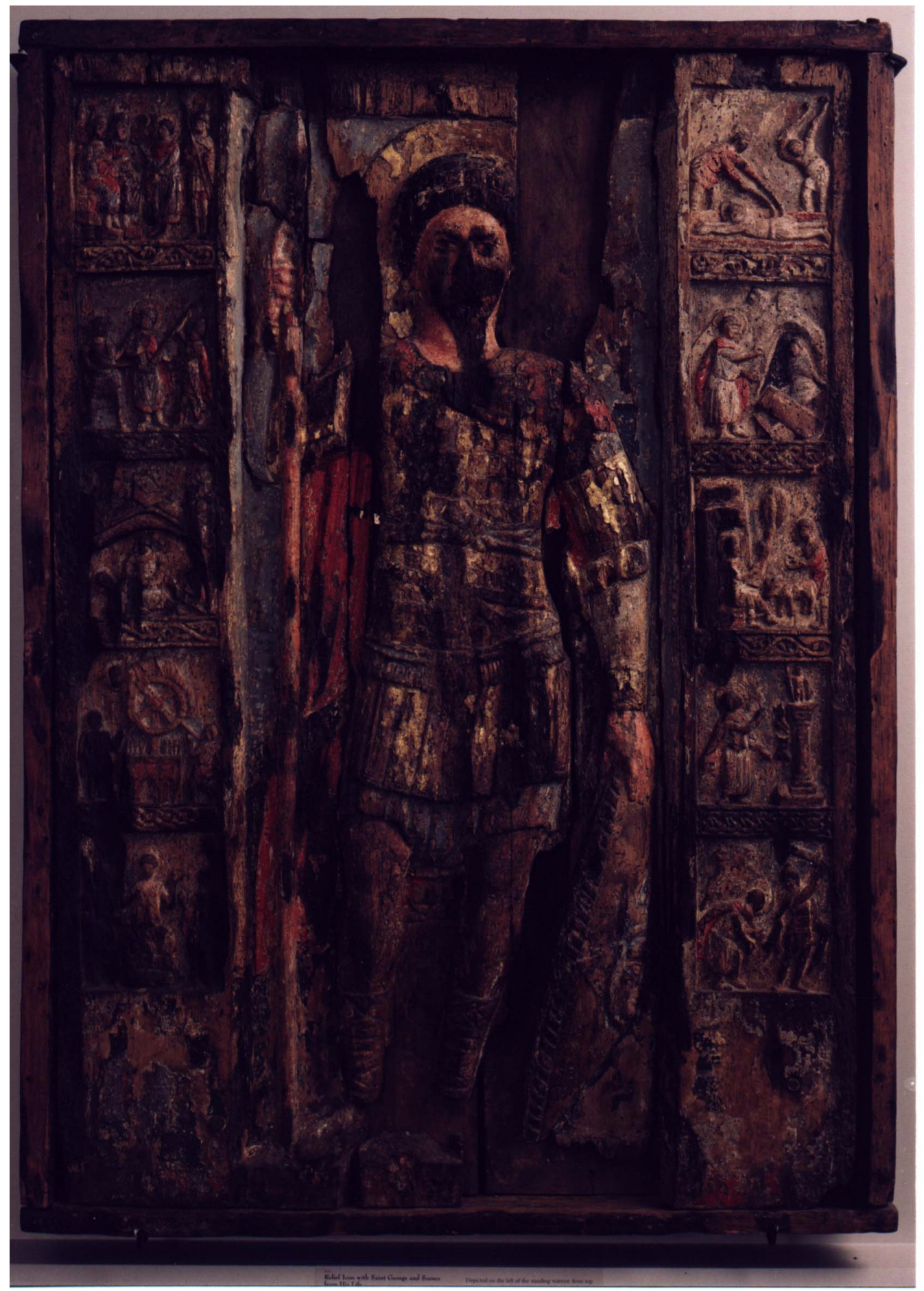

Figure 1 St George with scenes from his life 


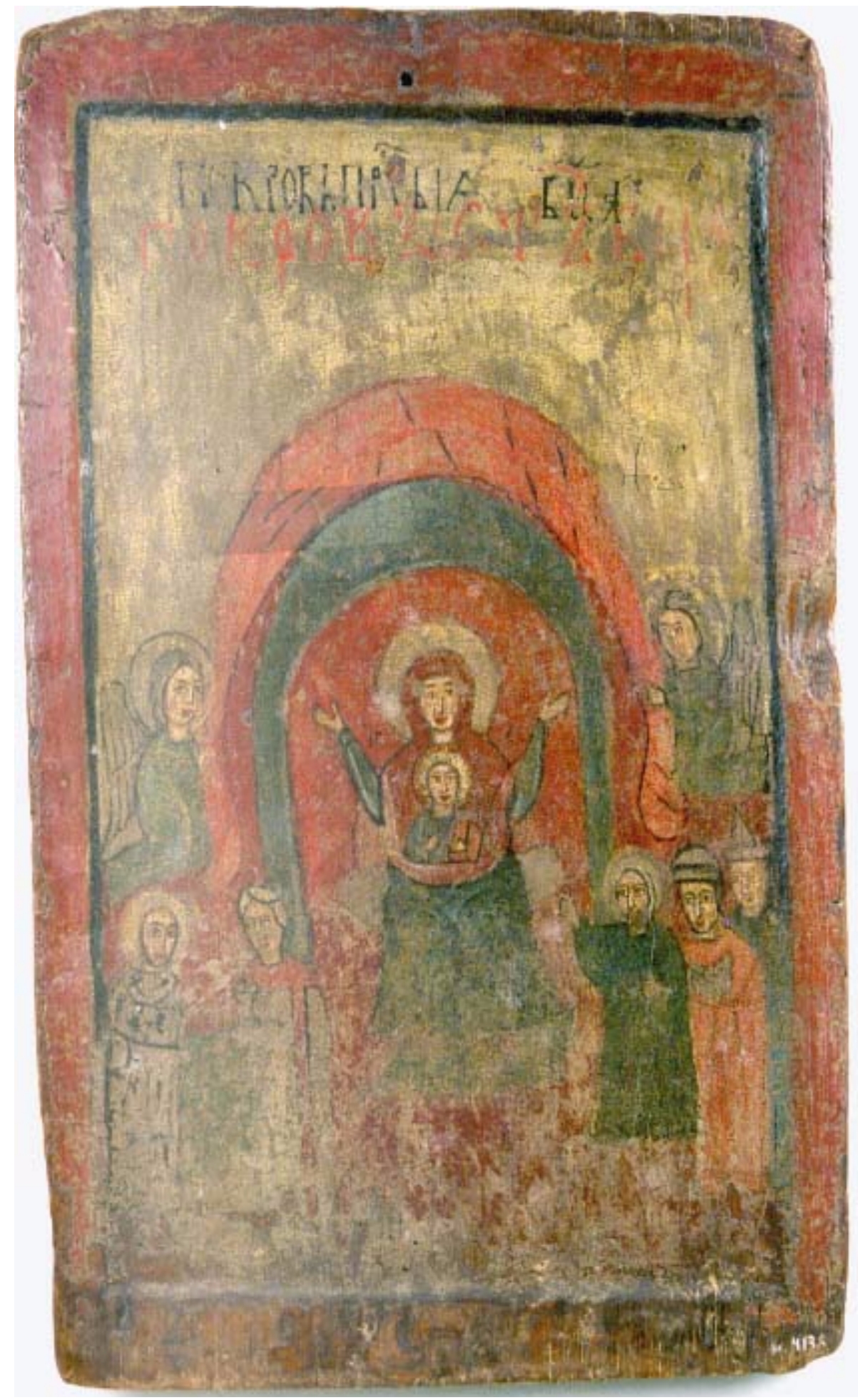

Figure 2 The Intercession 


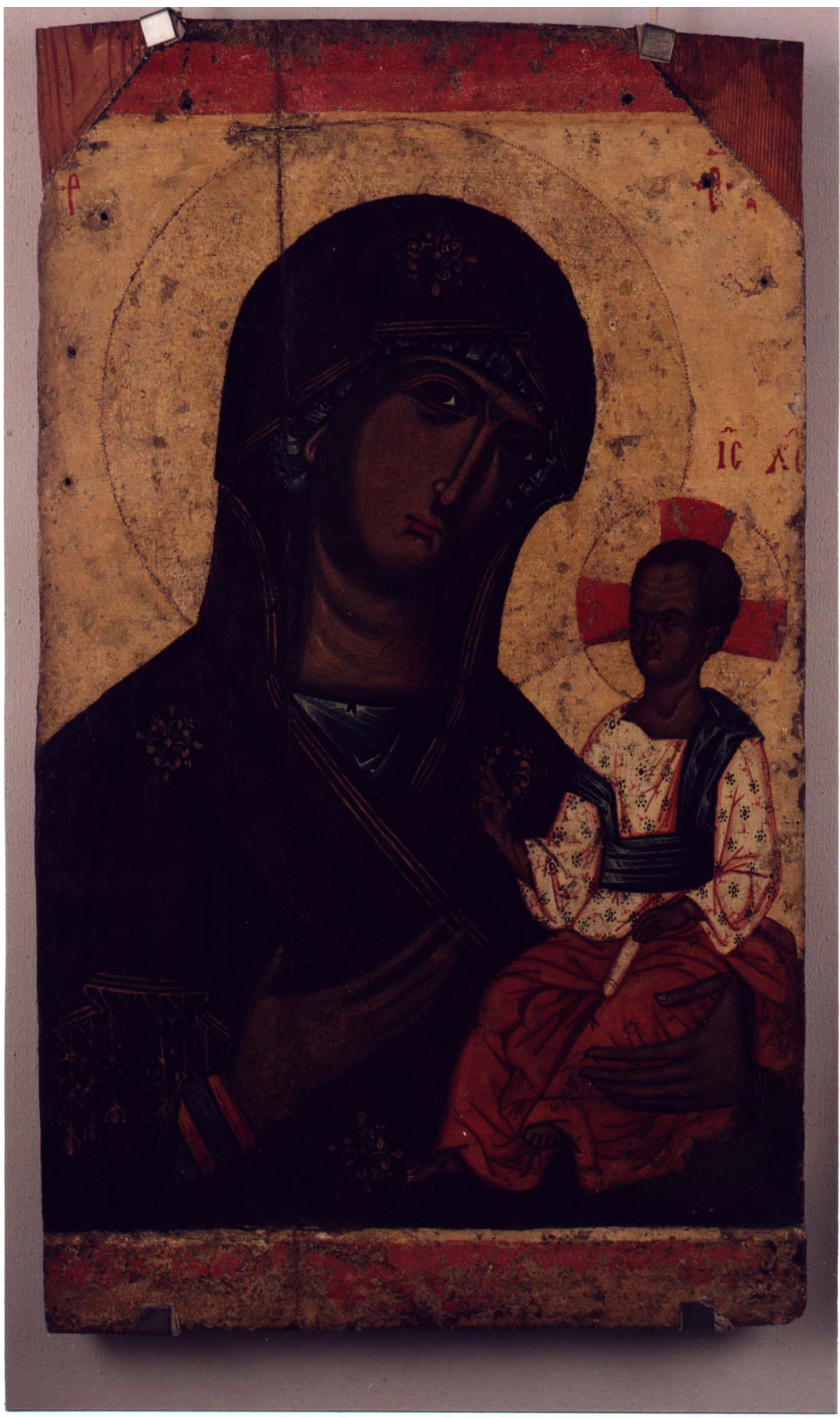

Figure 3 The Virgin Hodegetria of Volyn 




Figure 4 The Apostles Peter and Paul 


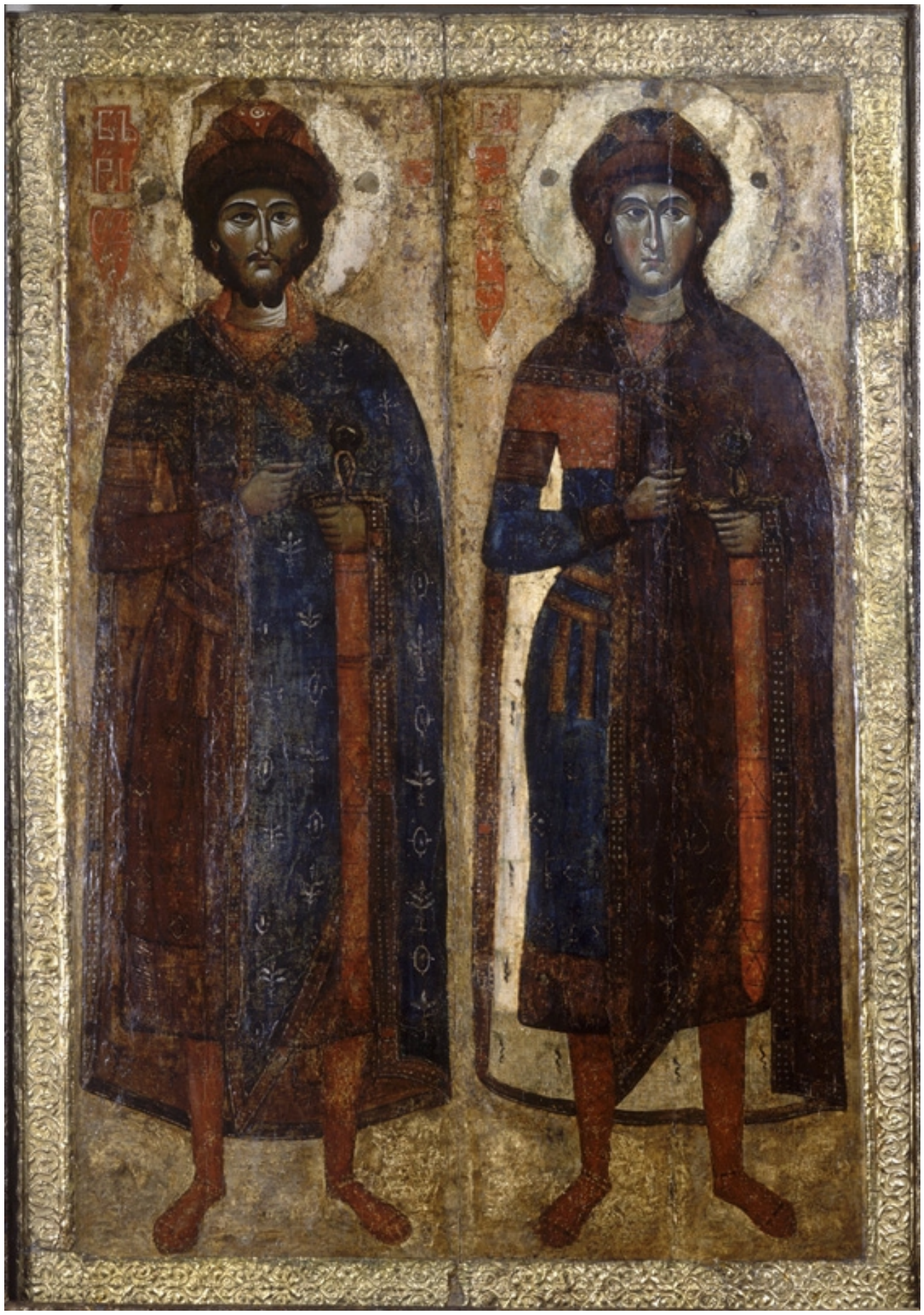

Figure 5 Boris and Gleb 


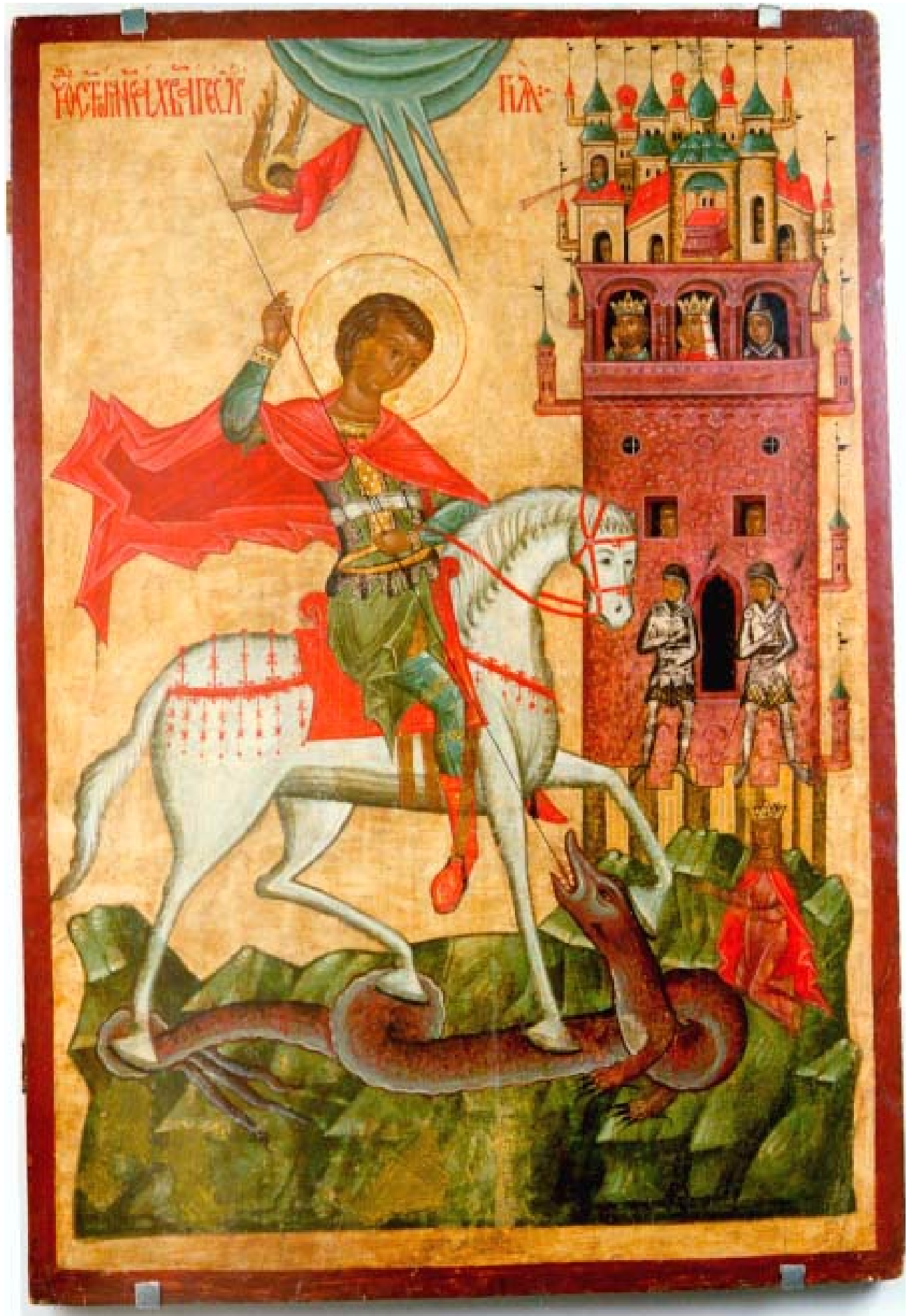

Figure 6 St George and the Dragon 


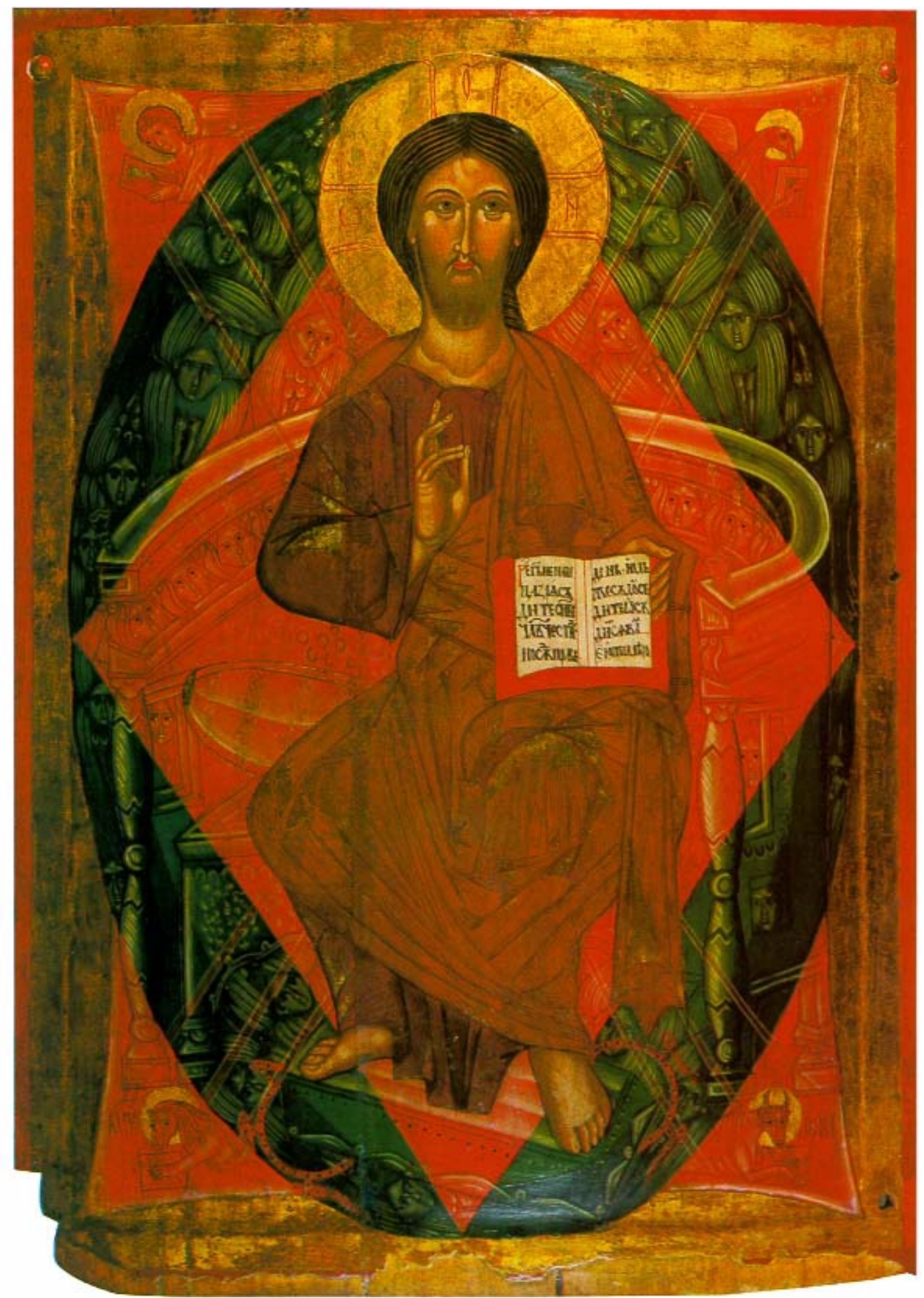

Figure 7 Christ in Majesty 